\title{
The role of adipokines in the pathogenesis and course of selected respiratory diseases
}

\author{
Artur Chwalba, Edyta Machura, Katarzyna Ziora, Dariusz Ziora \\ Pulmonology Branch Unit, Pulmonary Rehabilitation Independent Public Clinical Hospital No. 1, Silesian Medical University \\ in Katowice, Zabrze, Poland
}

\begin{abstract}
Adipose tissue is also a secretory organ producing active substances called adipokines. Some of them (apelin, resistin, adiponectin, leptin, chemerin, or visfatin) may play a role in the pathogenesis and course of respiratory diseases, e.g. COPD, asthma, pulmonary hypertension, or lung cancer. There are limited and conflicting data on the role of adipokines in asthma. It has been confirmed, however, that visfatin and leptin can be markers of inflammation in COPD. Elevated concentrations of leptin and resistin play a pro-inflammatory role in the development of cancer cachexia. The role of adipokines has also been demonstrated in pulmonary hypertension, and the apelinadiponectin axis disruption may exacerbate pulmonary hypertension. (Endokrynol Pol 2019; 70 (6): 504-441)
\end{abstract}

Key words: adipokines; apelin; resistin; adiponectin; leptin; chemerin; visfatin; nesfatin; COPD; pulmonary hypertension; non-small cell lung cancer

\section{Introduction}

Energy and insolating functions are not the only functions of fat tissue. It is also a secretory organ producing active substances called adipokines (Tab. I). It takes part in hunger regulation and maintenance of metabolic homeostasis, coordinates neuroendocrine and immunological functions, and is a place of steroid and thyroid hormones metabolism. White adipose tissue (WAT) participates in hormonal and inflammatory processes (through cardiovascular protection or neoangiogenesis). Functions of visceral adipose tissue (VAT) are different; it is located within organs (e.g. kidneys) and muscles, in the epicardium, and inside blood vessels. It is responsible for local (in the epicardium) and generalised inflammation, and - in muscles - for insulin resistance. Intravascular WAT affects the development of atherosclerosis and hypertension, and in kidneys - an increase in the intravascular pressure. White adipose tissue functions are performed by the secretion of leptin, omentin, adiponectin, resistin, visfatin, apelin, vaspin, hepcidin, chemerin, tumor necrosis factor alpha (TNF- $\alpha$ ), interleukin 6 (IL-6), monocyte chemoattractant protein-1 (MCP-1), and plasminogen activator inhibitor-1 (PAI-1), as well as the retinol binding protein 4 (RBP-4) [1]. In the 1940s a hypothesis was established that the interaction between adipose tissue and other tissues is bi-directional. A breakthrough came in 1994, when Friedman et al. [2] discovered leptin produced by mature adipocytes. Currently, adipose tissue is considered to be an endocrine organ synthesising adipokines that act in adipose tissue (autocrine and paracrine effects) and distant organs and tissues (classic endocrine activity) [3, 4]. Visceral adiposity is associated with decreased serum adiponectin levels, peripheral resistance to insulin, and an increased risk of cardio-metabolic complications [5]. Adiponectin was also linked with an anti-inflammatory, anti-oxidative, and metabolism regulating functions $[6,7]$.

Changes in nutritional status and fat content may influence hormonal activity of adipose tissue. The majority of research has focused on obesity and its impact on the adipokine profile [9]. Considerably fewer papers focus on the adipokine pattern in respiratory diseases. The following is a review of the literature on the role of some adipokines in the pathogenesis and course of respiratory diseases in humans and in animal models.

\section{Bronchial asthma}

The pathogenic relationship between asthma and obesity in humans is not fully understood. 
Table I. Biologically active proteins produced by adipocytes [5]

\begin{tabular}{|c|c|c|c|}
\hline Adipokine & Physiological functions & $\begin{array}{l}\text { Secretion } \\
\text { in obesity }\end{array}$ & Controversies \\
\hline \multicolumn{4}{|c|}{ Energy homeostasis } \\
\hline Leptin & $\begin{array}{l}\text { Beneficial effect: } \\
\uparrow \text { energy expenditure } \\
\downarrow \text { energy supply }\end{array}$ & $\uparrow$ & $\begin{array}{l}\text { Most obese people are not sensitive to endogenously } \\
\text { produced leptin }\end{array}$ \\
\hline \multicolumn{4}{|c|}{ Glucose homeostasis } \\
\hline Adiponectin & $\begin{array}{l}\text { Beneficial effect: } \\
\uparrow \text { glucose uptake and oxidation } \\
\downarrow \text { gluconeogenesis } \\
\uparrow \text { insulin sensitivity }\end{array}$ & $\downarrow$ & $\begin{array}{l}\text { Disturbed synthesis and secretion of adiponectin } \\
\text { in obese subjects may lead to the development } \\
\text { of insulin resistance and type } 2 \text { diabetes }\end{array}$ \\
\hline Omentin & $\begin{array}{l}\text { Beneficial effect: } \\
\uparrow \text { glucose uptake } \\
\uparrow \text { insulin sensitivity }\end{array}$ & $\downarrow$ & $\begin{array}{l}\text { Reduced secretion of omentin can be a risk factor for } \\
\text { metabolic syndrome }\end{array}$ \\
\hline Resistin & $\begin{array}{l}\text { Adverse effect: } \\
\uparrow \text { gluconeogenesis } \\
\downarrow \text { insulin sensitivity }\end{array}$ & $\uparrow$ & $\begin{array}{l}\text { Resistin can be a factor linking obesity } \\
\text { with the pathogenesis of type } 2 \text { diabetes }\end{array}$ \\
\hline Vaspin & $\begin{array}{l}\text { Beneficial effect: } \\
\uparrow \text { insulin sensitivity } \\
\downarrow \text { food intake (mechanism not fully understood) }\end{array}$ & $\uparrow$ & $\begin{array}{c}\text { Vaspin plays the role of a compensatory factor } \\
\text { in the case of increased metabolic complications } \\
\text { related to obesity }\end{array}$ \\
\hline Visfatin & $\begin{array}{l}\text { Beneficial effect: } \\
\uparrow \text { glucose uptake } \\
\uparrow \text { insulin sensitivity }\end{array}$ & $\uparrow$ & $\begin{array}{l}\text { Elevated visfatin levels in obese subjects may be due } \\
\text { to metabolic changes resulting from the compensatory } \\
\text { response to developing insulin resistance }\end{array}$ \\
\hline \multicolumn{4}{|c|}{ Cardiovascular system } \\
\hline Adiponectin & $\begin{array}{l}\text { Beneficial effect: } \\
\downarrow \text { endothelial adhesion molecules expression }\end{array}$ & $\downarrow$ & $\begin{array}{l}\text { Hypoadiponectinaemia in obesity does not protect } \\
\text { the vascular endothelium against inflammatory } \\
\text { and atherogenic changes; it is a risk factor for } \\
\text { cardiovascular complications }\end{array}$ \\
\hline Apelin & $\begin{array}{l}\text { Beneficial effect: } \\
\uparrow \text { cardiac contractility } \\
\downarrow \text { blood pressure }\end{array}$ & $\uparrow$ & $\begin{array}{l}\text { Apelin may have anti-obesity and antidiabetic effects. } \\
\text { An apelin increase in obesity may be the result } \\
\text { of inflammation and oxidative stress. }\end{array}$ \\
\hline \multicolumn{4}{|l|}{ Inflammation } \\
\hline Adiponectin & $\begin{array}{l}\text { Beneficial effect: } \\
\downarrow \text { TNF- } \alpha \text { synthesis and activity and NF- } \kappa \text { B activation }\end{array}$ & $\downarrow$ & $\begin{array}{l}\text { In obesity, adiponectin production decreases, which } \\
\text { favours the pro-inflammatory effect of TNF- } \alpha\end{array}$ \\
\hline Chemerin & $\begin{array}{l}\text { Controversial effect: } \\
\downarrow \text { production of proinflammatory cytokines (TNF- } \alpha, \text { IL-6) } \\
\uparrow \text { adiponectin synthesis } \\
\uparrow \text { immune cells chemotaxis to areas of inflammation }\end{array}$ & $\uparrow$ & $\begin{array}{l}\text { The chemerin blood concentration increase } \\
\text { is associated with characteristic features } \\
\text { of the metabolic syndrome; hence, chemerin } \\
\text { can serve as a biomarker of this disease. }\end{array}$ \\
\hline Omentin & $\begin{array}{l}\text { Beneficial effect: } \\
\downarrow \text { TNF- } \alpha \text { and NF- } \kappa \text { B activity }\end{array}$ & $\downarrow$ & $\begin{array}{l}\text { In obesity, omentin secretion decreases, which favours } \\
\text { the pro-inflammatory effect of TNF- } \alpha\end{array}$ \\
\hline Leptin & $\begin{array}{l}\text { Adverse effect: } \\
\uparrow \text { production of proinflammatory cytokines (TNF- } \alpha, \text { IL-6) }\end{array}$ & $\uparrow$ & \\
\hline
\end{tabular}

TNF- $\alpha$ — tumour necrosis factor alpha; IL-6 — interleukin 6 ; NF- $\kappa$ B — nuclear factor kappa beta

It is known that obesity leads to systemic inflammation, resulting in an increase of the concentration of adipokines, among others. Obesity adversely affects the susceptibility and capacity of the lungs and the diameter of the peripheral airways; it may also cause an increase in the airway hyperresponsiveness. Obese patients often have more severe asthma and a partial resistance to inhaled glucocorticoids. Better asthma 
control occurs after weight reduction in obese patients [10].

Data on the role of adipokines in bronchial asthma are, however, often contradictory.

The concentrations of one of the forms of apelin (APE-12) have been evaluated in the serum of healthy children and patients with bronchial asthma with normal body mass as well as in obese patients.

The mean APE-12 concentrations in obese patients both with and without asthma were significantly higher than in healthy children, regardless of gender. There was no relationship between the adipokine concentration and the severity of asthma and allergy, spirometric parameters, and BMI. Increased APE-12 content in obese children suggests that apelin may be involved in the pathogenesis of asthma [11].

Another study analysed the role of visfatin in asthma: serum visfatin concentrations were significantly higher in the asthma group compared to healthy subjects [12].

In a cross-sectional observational study in adults with bronchial asthma, Australian clinicians evaluated the ratio of resistin to adiponectin as a function of disease severity, gender, and obesity, and after a 10-week weight loss in obese patients. The serum resistin concentration and the resistin/adiponectin concentration ratio were significantly higher in severe asthma as compared to the healthy group, as well as in patients with a mild and moderate disease course. In asthma patients the resistin concentration was not dependent on sex or obesity, while adiponectin levels were lower in men compared to women and in obese subjects compared to people with a normal BMI. As a result, the resistin/adiponectin ratio was significantly higher in obese and non-obese men and obese women as compared to non-obese women. The authors suggested that high resistin concentrations were a predictor of the risk of developing severe asthma, while the resistin/adiponectin ratio was a negative predictor of FEV1 in patients. Following weight loss, neither the concentration values of resistin and adiponectin nor the value of the resistin/adiponectin ratio were changed. However, a change in the body fat percentage was associated with a change of the resistin/adiponectin ratio [13].

Other authors also observed that resistin levels are significantly elevated in patients with asthma compared to healthy subjects; furthermore, they correlated with the severity of the disease [14]. In another study it was observed that mean concentrations of resistin in non-obese children with atopic asthma were significantly higher than in healthy children. After gender stratification only obese boys and boys with normal body weight had significantly higher serum resistin levels than boys in the control group. Girls with obesity and with normal weight, as well as girls from the control group, showed significantly higher resistin concentrations than boys from the respective groups. There was no relationship between adipokine concentrations and the severity of asthma and allergies, spirometric parameters, and BMI [15].

The aim of the study conducted in Portugal was to compare the content of leptin and resistin in serum in patients with overweight and asthma, in patients with a normal body weight, and in obese individuals without asthma. Leptin is mainly secreted by adipocytes, and serum concentrations directly correlate with adipose tissue mass [16]. Although the levels of both adipokines were higher in patients with overweight and asthma as compared to healthy overweight subjects, these differences were not significant. Patients with and without asthma and overweight $(\mathrm{BMI} \geq 25)$ and with an increased waist circumference showed a higher level of leptin [17].

In an animal model it was demonstrated that an increased concentration of adiponectin alleviates allergic inflammation of the airways and reduces the airway hyperresponsiveness. On the other hand, exogenous leptin administration causes increased hypersensitivity. These data - supported by observational studies in humans - suggest that a low concentration of adiponectin is associated with the risk of developing asthma in women and girls during puberty. High levels of adiponectin may be associated with a milder course of asthma in children and women. In contrast, high serum leptin levels are associated with a higher incidence and/or severity of asthma, especially in women, post-pubescent girls, and boys in the prepubertal period [18].

Elevated levels of leptin and reduced levels of adiponectin may be associated with asthma and allergies in children. Elevated leptin levels were associated with an increased incidence of asthma; this relationship was particularly strong in non-atopic asthma. There was no relationship between the leptin level and allergic rhinoconjunctivitis. A low level of adiponectin was associated with an increased incidence of atopic dermatitis and atopic eczema [19].

The relationship between obesity and asthma was also evaluated in a prospective study in Finland: after analysing data on allergies, smoking, and the levels of insulin, CRP, lipids, leptin, and adiponectin, the relationship between asthma and obesity in adults was confirmed. However, the role of leptin and adiponectin in the pathogenesis of asthma was not demonstrated [20].

In American studies, high levels of serum leptin were associated with the occurrence of asthma in adults, and it was demonstrated that obesity increases the risk of asthma, especially in women [21]. 
A probable relationship between asthma and obesity may be due to the immune modulation of adipokines. In men, higher concentrations of adiponectin were associated with lower levels of exhaled nitric oxide and simultaneously with an increased response to the bronchodilator [22].

Other observations indicate that leptin and adiponectin may be associated with obesity, regardless of the occurrence of asthma and its severity: it was demonstrated that the mean serum leptin values and adiponectin concentrations were similar in patients with asthma and in control subjects, but leptin levels were higher in women than in men with asthma. The value of the leptin/adiponectin concentration ratio was significantly higher in women than in men, and it positively correlated with the BMI of asthmatic patients [23]. French clinicians confirmed the relationship of obesity with the coexisting chronic WAT inflammation, as well as increased production of TNF- $\alpha$ and IL-6, which - through leptin and resistin overproductionmay have a pro-inflammatory effect on other organs — including lung tissue [24].

\section{Chronic obstructive pulmonary disease}

Patients with COPD often present with a chronic generalised inflammation process, as well as malnutrition. Elevated serum visfatin levels are observed in some inflammatory diseases, but their association with the nutritional status and inflammation in COPD remains unexplained. In COPD patients, some authors observed significantly lower BMI values, as well as a decreased adipose tissue volume and an elevated serum visfatin concentration compared to the control group. Together with increased levels of visfatin, elevated levels of CRP and TNF- $\alpha$ were also observed. However, there were no significant correlations between the concentration of visfatin and BMI or the percentage of adipose tissue in both groups [25].

Finnish scientists evaluated the relationship of nesfatin and visfatin with inflammation activity, severity of symptoms, and lung function in men with emphysema and COPD. IL-6, IL-8, TNF- $\alpha$, and MMP-9 concentrations and exhaled nitric oxide were also measured. The measurements were repeated in a subgroup of patients after four weeks of treatment with an inhaled corticosteroid. Visfatin and nesfatin concentrations correlated positively with the IL- 6 and TNF- $\alpha$ concentration in the blood. In addition, the nesfatin concentration correlated positively with the content of IL-8 in the serum of patients with COPD. Furthermore, visfatin concentration correlated negatively with the lung diffusion capacity. The adipokine concentration remained unchanged after treatment with inhaled corticosteroids [26]. Leptin and visfatin have been shown to affect mucus secretion in the airways, while resistin intensifies the mucin production [27].

The leptin concentration in serum of COPD patients correlated with the patients' BMI. Alterations in the leptin, TNF- $\alpha$, and prealbumin concentrations were observed in episodes of COPD exacerbations; however, they did not prove to be reliable markers of exacerbations, although the leptin and TNF- $\alpha$ levels were significantly higher in patients with exacerbation [28]. In patients with exacerbation, a significant positive correlation was also observed between the leptin and TNF- $\alpha$ levels, which may be associated with an increased overall inflammation [29].

In the meta-analysis of the literature on the role of leptin in COPD, attention was drawn to the relationship between the leptin concentration and BMI in patients with COPD during the disease stability. The correlation coefficient was low during exacerbations. A positive correlation between the leptin concentration and TNF$\alpha$ was found only in exacerbations. Most studies have indicated that leptin concentrations in stable COPD patients were not significantly different from those in the control group, but increased in exacerbations, albeit negligibly [30].

Attempts to determine the role of leptin in malnutrition of COPD patients indicated that leptin was not associated with weight loss and there was no significant relationship between TNF- $\alpha$ and leptin during the energy balance regulation in patients with COPD [31].

Adiponectin appears to be a potent marker of COPD exacerbation and of the response to treatment. It was demonstrated that serum adiponectin concentrations were significantly higher in patients with exacerbation of COPD as compared to the control group. A significant positive correlation was found between the adiponectin and IL-8 levels in patients with COPD, and a negative correlation with $\mathrm{FEV}_{1} \%$.

It was concluded that the measurement of the adiponectin level may be used to assess the severity and progression of the disease, and that it may become helpful in the stratification of risk and therapy [32].

Also, adiponectin levels in induced sputum, significantly higher than in healthy subjects, were increased in men with exacerbation. Both in the case of exacerbations and in the stable phase, adiponectin levels were positively correlated with IL- 8 and TNF- $\alpha$ in serum and induced sputum. In addition, in exacerbations the adiponectin levels depended on the percentage of neutrophils in induced sputum [33].

In another study, male patients with mild, moderate, severe, and very severe COPD with low body weights were analysed. Serum concentrations of adiponectin were higher in patients with COPD as compared to the 
control group. At the same time, no significant differences were found for leptin, IL- $1 \beta$, TNF- $\alpha$, and IL- 8 in the compared groups. Levels of IL- 6 and hsCRP were higher in the group with mild and moderate COPD than in the control group. With an increase in the adiponectin value, a decrease in the BMI and FEV1 values was observed [34].

Also in Japanese studies, significantly higher values of annual decreases of FEV1 correlated positively with high values of the serum concentrations of adiponectin and negatively with the leptin/adiponectin concentration ratio. Thus, according to the authors, systematic measurements of serum adipokines may be used in predicting the deterioration risk in the lung function in the COPD course [35].

\section{Lung cancer}

Obesity is associated with increased risk of various cancers including: breast, renal, colon, corpus uteri, and prostate [36]. There are also some signals linking lung cancer with adipokines activity. The aim of the study carried out in patients suffering from advanced non-small cell lung cancer was to estimate cancer cachexia with regard to the concentration of resistin and leptin. The evaluation of resistin and leptin concentrations in patients with advanced cancer, not treated previously with chemotherapy, showed significantly higher levels of resistin and lower levels of leptin in comparison to healthy individuals. Although leptin and resistin may play an important pro-inflammatory role in the cancer cachexia pathogenesis, their use as diagnostic or prognostic markers requires further research [37].

There is no conclusive evidence so far for the undisputed contribution of adipocytokines in cachexia development in advanced lung cancer [38].

However, there is evidence of the involvement of some adipocytokines in the development and progression of cancer. A correlation between the levels of leptin, adiponectin, as well as resistin and the nutritional status, and systemic inflammation in the course of cancer and in its terminal stage was observed.

The potential prognostic significance of these adipokines was demonstrated, as well. Adiponectin is the most commonly present adipokine in the tumour microenvironment, but its role in tumour progression remains unspecified. Using tumour cell lines, the effect of adiponectin on migration and invasion in non-small cell lung cancer was evaluated. The presence of adiponectin in the cancer cell environment inhibited their migratory and invasive abilities. Exogenous adiponectin significantly interfered with the migration and invasive capacity of cancer cells, suggesting that adiponectin could be an innovative form of therapy in non-small cell lung cancer [39].

Japanese clinicians assessed the relationship between the adiponectin levels and the presence of non-haematological adverse reactions in advanced non-small cell lung cancer after treatment with epidermal growth factor receptor tyrosine kinase inhibitors (EGFR-TKIs). Treatment with EGFR-TKIs affects the adiponectin level. The initial adiponectin level (at the time of diagnosis) influences adverse events caused by EGFR-TKIs [40].

A growing percentage of obese people in the population and the accompanying cancer risk increased the need to understand the pathogenesis of this relation, e.g. by the analysis of the molecular pathways activated by adiponectin and leptin. Adipokine deregulation in obesity and its influence on tumour progression and metastasis has become one of the areas of such research: altered levels of adipokines or altered expression of adipokine receptors in cancer can lead to disorders in further molecular pathways. Leptin and adiponectin generally cause opposite molecular effects: the relationship between an increased serum leptin concentration and tumour growth has been highlighted in epidemiological studies, while adiponectin may have inhibitory effects on tumour growth [41].

\section{Pulmonary arterial hypertension}

Apelin and adiponectin play a role in the regulation of homeostasis of the endothelium and smooth muscle cells. Apelin modulates endothelial nitric oxide synthase (eNOS) expression, induces eNOS-dependent vasodilatation, counteracts angiotensin-II mediated vasoconstriction, and has positive inotropic and cardioprotective effects [42]. Apelin and adiponectin are highly expressed in pulmonary vessels, but their function is not entirely clear. The participation of adipocytokines in the pulmonary arterial hypertension pathogenesis still needs to be clarified, although interesting observations have been made about the ELA protein (Elabela/Toddler), i.e. an endogenous apelin receptor agonist in the cardiovascular system of adults.

The goal of animal studies on rats was to find evidence of the contribution of this protein in the pathogenesis of pulmonary hypertension and to demonstrate the alleviation of hypertension symptoms as a result of the exogenous administration of ELA. The subcutaneous ELA protein administration reduced the systolic pressure in the pulmonary artery, decreased the right ventricular hypertrophy, and reduced the intensity of pulmonary remodelling in rats. The results of these studies indicate the beneficial effect of ELA protein on the inhibition of cardio-pulmonary remodelling in 
laboratory animals. Furthermore, they may be indicative of potential new possibilities of seeking effective therapies in people suffering from various forms of pulmonary hypertension [43] The apelin and adiponectin expression in pulmonary vessels is regulated by factors involved in the pathogenesis of PAH and is suppressed in the endothelial cells of pulmonary arteries in patients with PAH. Apelin has, therefore, been proposed as a potential biomarker for PAH [42]. The above conclusions are also confirmed by the observations of other authors [44].

It has been hypothesised that the signalling disruption of the apelin — adiponectin axis leads to increased vascular remodelling in PAH. It was found that mice exposed to chronic hypoxia and deprived of apelin developed more severe PAH symptoms compared to wild-type mice. A micro CT scan of the pulmonary arteries showed a significant reduction in microvascularisation in apelin-depleted mice; they also had a significantly reduced level of serum nitrates. In PAH patients, the levels of apelin were significantly lower than in the control group. These data show that the apelin-adiponectin axis disruption may exacerbate $\mathrm{PAH}$ and identify this pathway as a potentially important therapeutic target [44].

\section{Inflammations in the respiratory system}

The secretion of resistin and visfatin is increased during inflammation as a response to proinflammatory cytokines. Resin and visfatin may also contribute to inflammatory processes, triggering cytokine production, and thus may be an attractive target for new therapeutic strategies in inflammatory diseases of the respiratory system chronic [45].

In all patients with community-acquired pneumonia, both those who survived and those who died, it has been demonstrated that the visfatin concentration was significantly increased compared to the control group; visfatin has been recognised as an independent prognostic factor in determining the risk of death during 30 days of observation. Increased visfatin concentrations also correlated with the disease severity and other inflammatory markers [46].

The aim of a team of Polish transplantologists was to examine the concentrations of visfatin, irisin, and omentin in patients with end-stage lung disease (cystic fibrosis, COPD, and idiopathic pulmonary fibrosis) before and after lung transplantation. The omentin concentration significantly decreased within three days of transplantation, whereas the visfatin concentration dropped later, 30 days after the procedure. An effective lung transplant surgery contributes to the improvement of the impaired lung function parameters and to the inhibition of the ongoing inflammatory process leading to changes in the serum concentration of adipokines. Lowered levels of both adipokines persisted for a further two months. The irisin concentration did not change before or after the transplantation. An immunosuppressive therapy did not affect the levels of the analysed adipokines; however, its effect on the omentin and visfatin concentration cannot be excluded [47].

\section{Conclusion}

The role of adipocytokines in good health as well as in the context of four respiratory diseases: bronchial asthma, COPD, pneumonia, and cancer, was analysed. Further research is needed to clarify the functional - autocrine and/or paracrine - effects of adipocytokines in homeostasis and disease. There is also a need for further studies devoted to the mechanisms of their effect on respiratory diseases. It is crucial to distinguish the effects of adipokines in acute and chronic diseases, because there may be a slightly different impact and significance depending on the severity of the disease process.

\section{References}

1. Skowrońska B, Fichna M, Fichna P. Rola tkanki tłuszczowej w układzie dokrewnym. Endokrynologia, Otyłość i Zaburzenia Przemiany Materii. 2005; 1(3): 21-29.

2. Zhang Y, Proenca R, Maffei M, et al. Positional cloning of the mouse obese gene and its human homologue. Nature. 1994; 372(6505): 425-432, doi: 10.1038/372425a0, indexed in Pubmed: 7984236.

3. Trayhurn P, Wood IS. Adipokines: inflammation and the pleiotropic role of white adipose tissue. Br J Nutr. 2004; 92(3): 347-355, doi: 10.1079/bjn20041213, indexed in Pubmed: 15469638.

4. Cancello R, Tounian A, Poitou Ch, et al. Adiposity signals, genetic and body weight regulation in humans. Diabetes Metab. 2004; 30(3): 215-227, indexed in Pubmed: 15223973.

5. Sirbu AE, Buburuzan L, Kevorkian S, et al. Adiponectin expression in visceral adiposity is an important determinant of insulin resistance in morbid obesity. Endokrynol Pol. 2018; 69(3): 252-258, doi: 10.5603/EP.a2018.0026, indexed in Pubmed: 29645064.

6. Baranowska-Bik A, Kalisz M, Martyńska L, et al. Plasma adiponectin array in women with Alzheimer's disease. Endokrynol Pol. 2018; 69(5): 550-559, doi: 10.5603/EP.a2018.0055, indexed in Pubmed: 30117532

7. Machura E, Szczepańska M, Świętochowska E, et al. Evaluation of adipokines in children with cystic fibrosis. Endokrynol Pol. 2018; 69(2): 128-134, doi: 10.5603/EP.a2018.0007, indexed in Pubmed: 29465158.

8. Korek E, Krauss H. Nowe adipokiny o potencjalnym znaczeniu w patogenezie otyłości i zaburzeń metabolicznych. Postepy Hig Med Dosw (online). 2015; 69: 799-810.

9. Baranowska-Bik A, Baranowska B, Martyńska L, et al. Adipokine profile in patients with anorexia nervosa. Endokrynol Pol. 2017; 68(4): 422-429, doi: 10.5603/EP.a2017.0035, indexed in Pubmed: 28604943.

10. Ziora D, Sitek P, Machura E, et al. [Bronchial asthma in obesity - a distinct phenotype of asthma?]. Pneumonol Alergol Pol. 2012; 80(5): 454-462, indexed in Pubmed: 22926907.

11. Machura E, Ziora K, Ziora D, et al. Serum apelin-12 level is elevated in schoolchildren with atopic asthma. Respir Med. 2013; 107(2): 196-201, doi: 10.1016/j.rmed.2012.10.026, indexed in Pubmed: 23199840.

12. Toru Ü, Ayada C, Genç O, et al. Visfatin and ghrelin: can they be forthcoming biomarkers or new drug targets for asthma? Int J Clin Exp Med. 2015; 8(4): 6257-6261, indexed in Pubmed: 26131235.

13. Ballantyne $D$, Scott $H$, MacDonald-Wicks L, et al. Resistin is a predictor of asthma risk and resistin:adiponectin ratio is a negative predictor of lung function in asthma. Clin Exp Allergy. 2016; 46(8): 1056-1065, doi: 10.1111/cea.12742, indexed in Pubmed: 27079485.

14. Larochelle J, Freiler J, Dice J, et al. Plasma resistin levels in asthmatics as a marker of disease state. J Asthma. 2007; 44(7): 509-513, doi: 10.1080/02770900701495785, indexed in Pubmed: 17885852. 
15. Ziora D, Machura E, Ziora KT, et al. Serum resistin levels are elevated in schoolchildren with atopic asthma. Neuro Endocrinol Lett. 2013; 34(3): 212-216, indexed in Pubmed: 23685419.

16. Wojciechowska C, Jacheć W, Romuk E, et al. The effect of BMI, serum leptin, and adiponectin levels on prognosis in patients with non-ischaemic dilated cardiomyopathy. Endokrynol Pol. 2017; 68(1): 26-34, doi: 10.5603/EP.2017.0005, indexed in Pubmed: 28255978.

17. Muc M, Todo-Bom A, Mota-Pinto A, et al. Leptin and resistin in overweight patients with and without asthma. Allergol Immunopathol (Madr). 2014; 42(5): 415-421, doi: 10.1016/j.aller.2013.03.004, indexed in Pubmed: 23648099.

18. Sood A, Shore SA. Adiponectin, Leptin, and Resistin in Asthma: Basic Mechanisms through Population Studies. J Allergy (Cairo). 2013; 2013: 785835, doi: 10.1155/2013/785835, indexed in Pubmed: 24288549.

19. Nagel G, Koenig W, Rapp K, et al. Associations of adipokines with asthma, rhinoconjunctivitis, and eczema in German schoolchildren. Pediatr Allergy Immunol. 2009; 20(1): 81-88, doi: 10.1111/j.1399-3038.20 08.00740.x, indexed in Pubmed: 18331416.

20. Jartti T, Saarikoski L, Jartti L, et al. Obesity, adipokines and asthma. Allergy. 2009; 64(5): 770-777, doi: 10.1111/j.1398-9995.2008.01872.x, indexed in Pubmed: 19210351.

21. Sood A, Ford ES, Camargo CA. Association between leptin and asthma in adults. Thorax. 2006; 61(4): 300-305, doi: 10.1136/thx.2004.031468, indexed in Pubmed: 16540481.

22. Sutherland TJT, Sears MR, McLachlan CR, et al. Leptin, adiponectin, and asthma: findings from a population-based cohort study. Ann Allergy Asthma Immunol. 2009; 103(2): 101-107, doi: 10.1016/S1081-1206(10)60161-5, indexed in Pubmed: 19739421.

23. Jang AS, Kim TH, Park JS, et al. Association of serum leptin and adiponectin with obesity in asthmatics. J Asthma. 2009; 46(1): 59-63, doi: 10.1080/02770900802444203, indexed in Pubmed: 19191139.

24. Bastard JP, Maachi M, Lagathu C, et al. Recent advances in the relationship between obesity, inflammation, and insulin resistance. Eur Cytokine Netw. 2006; 17(1): 4-12, indexed in Pubmed: 16613757.

25. Liu X, Ji Y, Chen J, et al. Circulating visfatin in chronic obstructive pulmonary disease. Nutrition. 2009; 25(4): 373-378, doi: 10.1016/j. nut.2008.09.008, indexed in Pubmed: 19056239.

26. Leivo-Korpela S, Lehtimäki L, Hämälainen $\mathrm{M}$, et al. Adipokines NUCB2/nesfatin-1 and visfatin as novel inflammatory factors in chronic obstructive pulmonary disease. Mediators Inflamm. 2014; 2014: 232167, doi: 10.1155/2014/232167, indexed in Pubmed: 24891763.

27. Kwak S, Kim YD, Na HG, et al. Resistin upregulates MUC5AC/B mucin gene expression in human airway epithelial cells. Biochem Biophys Res Commun. 2018; 499(3): 655-661, doi: 10.1016/j.bbrc.2018.03.206, indexed in Pubmed: 29604272.

28. Mohan A, Arora S, Uniyal A, et al. Evaluation of plasma leptin, tumor necrosis factor- , and prealbumin as prognostic biomarkers during clinical recovery from acute exacerbations of chronic obstructive pulmonary disease. Lung India. 2017; 34(1): 3-8, doi: 10.4103/0970-2113.197101, indexed in Pubmed: 28144052.

29. Calikoglu M, Sahin G, Unlu A, et al. Leptin and TNF-alpha levels in patients with chronic obstructive pulmonary disease and their relationship to nutritional parameters. Respiration. 2004; 71(1): 45-50, doi: 10.1159/000075648, indexed in Pubmed: 14872110.

30. Zhou L, Yuan C, Zhang J, et al. Circulating leptin concentrations in patients with chronic obstructive pulmonary disease: a systematic review and meta-analysis. Respiration. 2013; 86(6): 512-522, doi: 10.1159/000354191, indexed in Pubmed: 24158120.

31. Yang YM, Sun TY, Liu XM. The role of serum leptin and tumor necrosis factor-alpha in malnutrition of male chronic obstructive pulmonary disease patients. Chin Med J (Engl). 2006; 119(8): 628-633, indexed in Pubmed: 16635406.
32. Jaswal S, Saini V, Kaur J, et al. Association of Adiponectin with Lung Function Impairment and Disease Severity in Chronic Obstructive Pulmonary Disease. Int J Appl Basic Med Res. 2018; 8(1): 14-18, doi: 10.4103/ijabmr. IJABMR 65 17, indexed in Pubmed: 29552529.

33. Xie J, Yang XY, Shi JD, et al. A new inflammation marker of chronic obstructive pulmonary disease-adiponectin. World J Emerg Med. 2010; 1(3): 190-195, indexed in Pubmed: 25214966.

34. Uzum AK, Aydin MM, Tutuncu Y, et al. Serum ghrelin and adiponectin levels are increased but serum leptin level is unchanged in low weight Chronic Obstructive Pulmonary Disease patients. Eur J Intern Med. 2014; 25(4): 364-369, doi: 10.1016/j.ejim.2013.02.012, indexed in Pubmed: 23523152.

35. Suzuki M, Makita H, Östling J, et al. Hokkaido COPD Cohort Study, Danish Lung Cancer Screening Trial Investigators. Lower leptin/adiponectin ratio and risk of rapid lung function decline in chronic obstructive pulmonary disease. Ann Am Thorac Soc. 2014; 11(10): 1511-1519, doi: 10.1513/AnnalsATS.201408-351OC, indexed in Pubmed: 25372271.

36. Siemińska L, Borowski A, Marek B, et al. Serum concentrations of adipokines in men with prostate cancer and benign prostate hyperplasia. Endokrynol Pol. 2018; 69(2): 120-127, doi: 10.5603/EP.a2018.0006, indexed in Pubmed: 29465157.

37. Demiray G, Değirmencioğlu S, Uğurlu E, et al. Effects of Serum Leptin and Resistin Levels on Cancer Cachexia in Patients With Advanced-Stage Non-Small Cell Lung Cancer. Clin Med Insights Oncol. 2017; 11: 1179554917690144, doi: 10.1177/1179554917690144, indexed in Pubmed: 28469508.

38. Ntikoudi E, Kiagia M, Boura P, et al. Hormones of adipose tissue and their biologic role in lung cancer. Cancer Treat Rev. 2014; 40(1): 22-30, doi: 10.1016/j.ctrv.2013.06.005, indexed in Pubmed: 23870486.

39. Cui E, Guo H, Shen Mo, et al. Adiponectin inhibits migration and invasion by reversing epithelial-mesenchymal transition in non-small cell lung carcinoma. Oncol Rep. 2018; 40(3): 1330-1338, doi: 10.3892/or.2018.6523, indexed in Pubmed: 29956809.

40. Umekawa K, Kimura T, Kudoh S, et al. Reaction of plasma adiponectin level in non-small cell lung cancer patients treated with EGFR-TKIs. Osaka City Med J. 2013; 59(1): 53-60, indexed in Pubmed: 23909081.

41. Vansaun MN. Molecular pathways: adiponectin and leptin signaling in cancer. Clin Cancer Res. 2013; 19(8): 1926-1932, doi: 10.1158/1078-0432. CCR-12-0930, indexed in Pubmed: 23355630.

42. Andersen CU, Hilberg O, Mellemkjær S, et al. Apelin and pulmonary hypertension. Pulm Circ. 2011; 1(3): 334-346, doi: 10.4103/2045-8932.87299, indexed in Pubmed: 22140623.

43. Yang P, Read C, Kuc RE, et al. Elabela/Toddler Is an Endogenous Agonist of the Apelin APJ Receptor in the Adult Cardiovascular System, and Exogenous Administration of the Peptide Compensates for the Downregulation of Its Expression in Pulmonary Arterial Hypertension. Circulation. 2017; 135(12): 1160-1173, doi: 10.1161/CIRCULATIONAHA.116.023218, indexed in Pubmed: 28137936.

44. Chandra SM, Razavi H, Kim J, et al. Disruption of the apelin-APJ system worsens hypoxia-induced pulmonary hypertension. Arterioscler Thromb Vasc Biol. 2011; 31(4): 814-820, doi: 10.1161/ATVBAHA.110.219980, indexed in Pubmed: 21233449.

45. Stofkova A. Resistin and visfatin: regulators of insulin sensitivity, inflammation and immunity. Endocr Regul. 2010; 44(1): 25-36, indexed in Pubmed: 20151765.

46. Hu W, Liu CW, Su J, et al. Elevated plasma visfatin concentrations in patients with community-acquired pneumonia. Peptides. 2013; 43: 8-12, doi: 10.1016/j.peptides.2013.02.017, indexed in Pubmed: 23466352.

47. Ochman M, Maruszewski M, Wojarski J, et al. Serum Levels of Visfatin, Omentin and Irisin in Patients with End-Stage Lung Disease Before and After Lung Transplantation. Ann Transplant. 2017; 22: 761-768, doi: 10.12659/aot.904994, indexed in Pubmed: 29277835. 